\title{
Growth hormone deficiency in a girl with the Cohen syndrome
}

\author{
G Massa, L Dooms, M Vanderschueren-Lodeweyckx
}

\begin{abstract}
A girl with the Cohen syndrome and isolated growth hormone deficiency is described. Treatment with biosynthetic human growth hormone resulted in marked catch up growth to normal stature. It is concluded that growth hormone deficiency should be ruled out in patients with the Cohen syndrome and small stature.
\end{abstract}

The Cohen syndrome is a rare disorder characterised by a typical craniofacial appearance, slender, tapering fingers and toes, obesity of mid-childhood onset, mental retardation, and hypotonia. ${ }^{12}$ Although about $70 \%$ of reported cases have growth retardation and delayed puberty, ${ }^{2-7}$ no endocrine abnormalities have been reported so far, apart from isolated gonadotrophin deficiency in one patient. ${ }^{2}$ We report a patient with the Cohen syndrome and isolated growth hormone (GH) deficiency.

\section{Case report}

The proband, a girl, is the second child of healthy, unrelated parents with normal stature (father's height $175 \mathrm{~cm}$ (25th to 50th centile) and mother's height 165 $\mathrm{cm}$ (50th to 75th centile)). The family history is unremarkable. The child was born at term with a birth weight of $3500 \mathrm{~g}$ (75th centile) and length of 52

Section of Paediatric and Adolescent Endocrinology, Department of Paediatrics, University of Leuven, Leuven, Belgium.

G Massa, L Dooms, M Vanderschueren-Lodeweyckx

Correspondence to Dr Massa, Department of Paediatric Endocrinology, UZ Gasthuisberg, Herestraat 49, B3000 Leuven, Belgium.

Received for publication 15 February 1990.

Revised version accepted for publication 4 June 1990. cm (97th centile). In the neonatal period feeding problems were encountered with failure to thrive. Developmental milestones were slightly delayed.

At the age of 12 years 2 months the patient was referred for evaluation of speech problems. Height was $134.9 \mathrm{~cm}$ ( $2 \mathrm{~cm}$ below the 3 rd centile), weight $32 \cdot 7 \mathrm{~kg}$ ( $109 \%$ of ideal body weight (IBW)), and head circumference $52 \mathrm{~cm}$ (25th centile). Physical examination showed several dysmorphic features (fig 1)

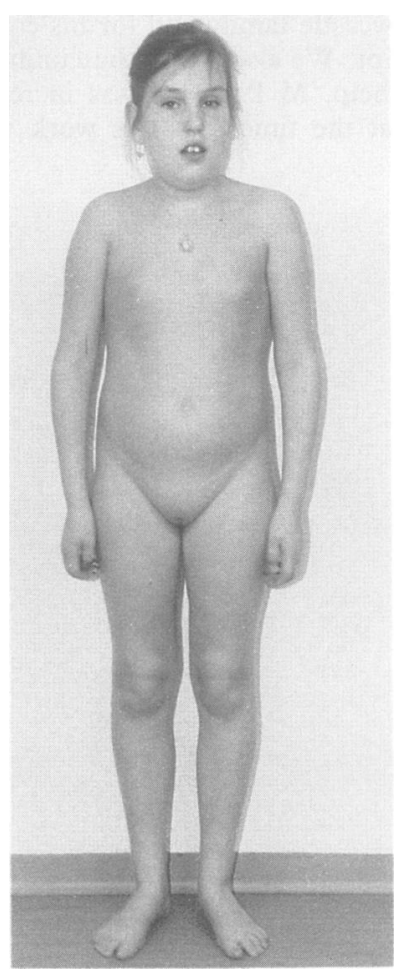

Figure 1 The patient aged 12 years 2 months. 


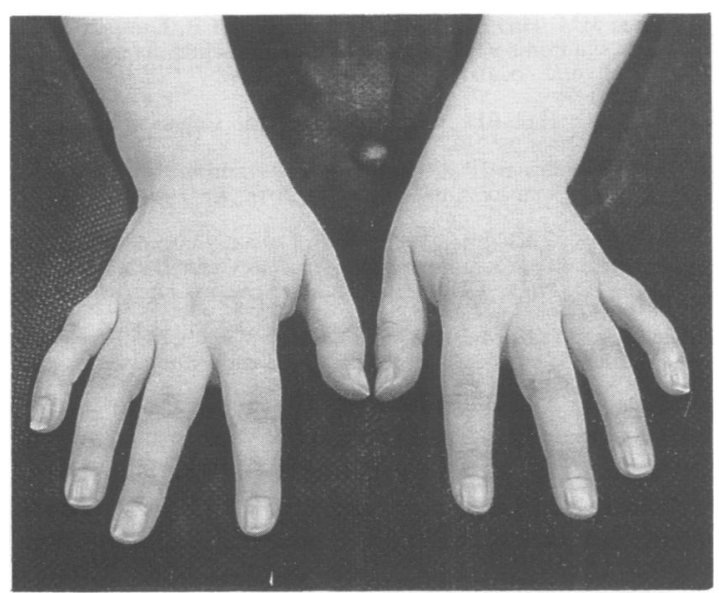

Figure 2 Hands of the patient showing small size and tapering fingers.

including truncal obesity, micrognathia, maxillary hypoplasia, open mouth with prominent maxillary central incisors, high nasal bridge, short philtrum, and narrow hands (fig 2) and feet. On neurological examination, mild general hypotonia and hypermobility of the joints was noted. Ophthalmological evaluation showed an antimongoloid slant and divergent strabismus. Examination of the eye fundus was normal. Psychometric testing gave an IQ of 101 (verbal 94, performance 110). These features led to a diagnosis of Cohen syndrome.

At the age of 13 years 5 months, her height was $137.5 \mathrm{~cm}(7 \mathrm{~cm}$ below the $3 \mathrm{rd}$ centile), weight $30.7 \mathrm{~kg}$ ( $97 \%$ of IBW), and pubertal score according to Tanner $^{8}$ was A1P1M2. Height velocity over the previous year was $2.6 \mathrm{~cm}$. Bone age, according to the method of Tanner et al, ${ }^{9}$ was $\mathbf{9 \cdot 1}$ 'years'. Laboratory investigations, including routine blood and urine chemistry, yielded normal results. The patient did not

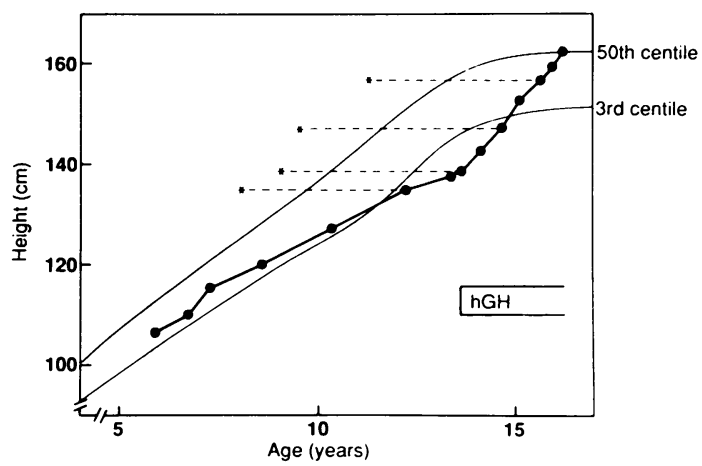

Figure 3 Growth chart of the patient. The bone age is indicated by an asterisk. have neutropenia. Measurements of circulating levels of thyroid hormones and cortisol were normal. Maximal serum GH levels after insulin induced hypoglycaemia and glucagon were $4.4 \mu \mathrm{g} / \mathrm{l}$ and 6.1 $\mu \mathrm{g} / \mathrm{l}$, respectively, indicating $\mathrm{GH}$ deficiency. The GH releasing hormone test showed a peak GH level of 3.6 $\mu \mathrm{g} / \mathrm{l}$. Plasma somatomedin $\mathrm{C}$, measured by radioimmunoassay, was $0.3 \mathrm{IU} / \mathrm{ml}$. The luteinising hormone releasing hormone (LHRH) test showed a peak level of $7.5 \mathrm{IU} / \mathrm{l}$ for $\mathrm{LH}$ and of $29.0 \mathrm{IU} / 1$ for $\mathrm{FSH}$, compatible with a pubertal response. Therefore, the diagnosis of isolated GH deficiency was made. Treatment with recombinant hGH (Somatonorm, Kabi, Sweden) in a dose of $3 \times 6 \mathrm{IU}$ per week intramuscularly was initiated resulting in a clear cut catch up growth (fig 3). After two and a half years of treatment, her height was $162.1 \mathrm{~cm}$ (50th centile) and weight $51.5 \mathrm{~kg}$ ( $93 \%$ of IBW). Puberty progressed slowly to Tanner stage A1P2M4 with menarche at the age of 16 years 8 months.

\section{Discussion}

The patient reported here had several major and minor characteristics of the Cohen syndrome, including short stature, truncal obesity, hypotonia, characteristic craniofacial morphology, and narrow hands and feet. In addition, endocrine studies showed isolated GH deficiency. Treatment with hGH resulted in marked catch up growth.

Most patients with the Cohen syndrome have a complex growth disorder with small stature, delayed bone maturation, truncal obesity, and delayed puberty. ${ }^{2-7}$ Although the cause of these findings is unclear, they are comparable to those found in patients with GH deficiency. ${ }^{10}$ Despite this, only a few authors have studied GH secretion in patients with the Cohen syndrome. The second patient reported by Carey and Hall ${ }^{2}$ had short stature and delayed bone maturation, but a normal response of GH to stimulation tests with arginine and insulin. The two patients reported by Ferré $e t a l^{3}$ were small with normal endocrine findings, but no details were given about GH secretion. Resnick et $a l^{4}$ reported one patient with low normal GH levels with no increase after stimulation with L-dopa. Since the somatomedin levels were normal in this patient, these authors suggested that the growth disturbance represented target organ failure. The patient we report here clearly has a subnormal response of GH to pharmacological testing.

Among the reported patients with the Cohen syndrome, $83 \%$ have delayed puberty. ${ }^{5}$ In only one patient has gonadotrophin deficiency been documented $^{2}$; in the others evaluated, the secretion of gonadotrophins was normal ${ }^{6}$ or low for age. ${ }^{7}$ The onset of puberty was late in our patient and puberty progressed slowly. These findings are comparable to 
those reported in girls with isolated GH deficiency. ${ }^{11}$ Although the differential diagnosis with constitutional delay of growth and puberty is not obvious, the marked catch up growth observed during hGH therapy is likely to be caused by hGH. Moreover, the GH releasing hormone test did not result in any GH secretion, suggesting a pituitary involvement. We therefore assume that, in our patient, GH deficiency was a major factor contributing to the short stature.

The findings described here suggest that, at least in some patients with the Cohen syndrome, a hypothalamohypophyseal neuroendocrine developmental disturbance is present with insufficient GH secretion. It therefore seems appropriate to evaluate GH secretion in these patients with short stature and to propose a therapeutic trial with hGH.

The authors thank Professor P Casaer and Dr B Ceulemans, Paediatric Neurologists, for referral of the patient, and Professor J P Fryns for valuable discussion. Part of this work was supported by a grant from the Belgian 'Nationaal Fonds voor Geneeskundig Wetenschappelijk Onderzoek' (3.0047.89).
1 Cohen MM, Hall BD, Smith DW, Graham CB, Lampert KJ. A new syndrome with hypotonia, obesity, mental deficiency, and facial, oral, ocular, and limb anomalies. $f$ Pediatr 1973;83: $280-4$.

2 Carey JC, Hall BD. Confirmation of the Cohen syndrome. $f$ Pediatr 1978;93:239 44.

3 Ferré F, Fournet JP, Courpotin C. Le syndrome de Cohen, une affection autosomique récessive? Arch Fr Pediatr 1982;39: $159-60$.

4 Resnick K, Zuckerman J, Cotlier E. Cohen syndrome with bull's eye macular lesion. Ophthalmic Paediatr Genet 1986;7:1-8.

5 Young ID, Moore JR. Intrafamilial variation in Cohen syndrome. f Med Genet 1987;24:488-92.

6 Balestrazzi P, Corrini L, Villani G, Bolla MP, Casa F, Bernasconi $S$. The Cohen syndrome: clinical and endocrinological studies of two new cases. 7 Med Genet 1980;17:430-2.

7 Goecke T, Majewski F, Kauther KD, Sterzel U. Mental retardation, hypotonia, obesity, ocular, facial, dental, and limb abnormalities (Cohen syndrome). Eur $\mathcal{F}$ Pediatr 1982;138: $338-40$.

8 Tanner JM. Growth at adolescence. 2nd ed. Oxford: Blackwell, 1962.

9 Tanner JM, Whitehouse RH, Marshall WA, Healy MJR, Goldstein H. Assessment of skeletal maturity and prediction of adult height. New York: Academic Press, 1975.

10 Brook CGD, Hindmarsh PC, Smith PJ, Stanhope R. Clinical features and investigation of growth hormone deficiency. Clin Endocrinol Metab 1986;15:479-93.

11 Frisch H, Schober E, Waldhouser F, Häusler G. Puberty in isolated growth hormone deficiency. In: Frisch $\mathrm{H}$, Laron Z, eds. Induction of puberty in hypopituitarism. Rome: Ares Serono Symposia Review No 16. 1987:49-63. 